\title{
Comparative Study of Fractions from Alkaline Extraction of Wheat Straw through Chemical Degradation, Analytical Pyrolysis, and Spectroscopic Techniques
}

\author{
María L. Fidalgo, ${ }^{\dagger}$ María C. Terrón, ${ }^{\dagger}$ Angel T. Martínez, ${ }^{\dagger}$ Aldo E. González,,$+\dagger$ \\ Francisco J. González-Vila, ${ }^{\dagger}$ and Guido C. Gallettis
}

Centro de Investigaciones Biológicas, CSIC, Velázquez 144, E-28006 Madrid, Spain, Instituto de Recursos Naturales y Agrobiología, CSIC, P.O. Box 1052, E-41080 Sevilla, Spain, Istituto di Microbiologia e Tecnologia Agraria e Forestale, University of Reggio Calabria, I-89061 Gallina (RC), Italy

\begin{abstract}
A comparative assessment of spectroscopic and degradative techniques was carried out to characterize fractions from the sodium hydroxide extraction of wheat straw. CPMAS ${ }^{13} \mathrm{C}$ NMR and IR spectra revealed lignin, lignin-carbohydrate complex, and hemicellulose in laboratory and industrial fractions. Preferential removal by alkali of syringyl lignin was observed, and lignin alteration during biological treatment of pulping effluents was indicated by enhanced carbonyl and alkyl signals. Relatively high syringyl/guaiacyl ratio values were obtained by cupric oxide degradation when compared with those from NMR and Py-GC-MS, the latter including ferulic acid. Additional information on straw polymer association and the role of cinnamic acids was obtained. The high guaiacyl content in lignin associated to the hemicellulose suggested bonds between the latter and guaiacyl lignin. Most linked $p$-coumaric acid was merely esterified, whereas ferulic acid was preferentially associated to lignin by nonsaponifiable bonds.
\end{abstract}

The limitations of present analytical methodologies for characterizing complex biopolymers represents an important drawback in the study of lignocellulosic materials. In the case of grass lignins, additional problems arise from their structural complexity due to the simultaneous presence of $p$-hydroxyphenyl $(\mathrm{H})$, guaiacyl $(\mathrm{G})$, and syringyl (S) units, in chemical association with cinnamic acids (Higuchi, 1990). Analytical pyrolysis has proven to be a quick and useful technique to analyze lignincontaining materials since, although the side chain of lignin units is modified, the groups attached to the aromatic ring remain unaltered (Boon, 1989). On the other hand, $\mathrm{CuO}$ alkaline oxidation is a suitable degradative procedure to analyze grass lignins since, as opposed to pyrolysis, it allows the identification of cinnamic acids (Hedges and Ertel, 1982). Finally, spectroscopic techniques, such as NMR and IR, are complementary to the above degradative procedures (Martínez et al., 1991a) since they provide information on the whole structure of the polymer and avoid the possibility of degradation artifacts. Moreover, solid-state NMR of lignocellulosic materials using CPMAS ${ }^{13} \mathrm{C}$ NMR (Fründ and Lüdemann, 1989a) eliminates methodological troubles related to previous extraction and solubilization for solution NMR.

Cereal straws represent alternative raw materials for the production of some types of paper pulp, especially in areas with limited forest resources (Marley, 1991). Some attempts to characterize straw lignins and lignin-carbohydrate complexes from soda pulping have been reported (Xiao-an et al., 1989). However, additional information concerning composition and distribution of straw polymers in fractions obtained during alkali treatment could permit

* Author to whom correspondence should be addressed (phone 341 5611800; fax 341 5627518; E-mail CIBAT38@CC.CSIC.ES).

† Centro de Investigaciones Biológicas.

$\ddagger$ Instituto de Recursos Naturales y Agrobiología.

Istituto di Microbiologia e Tecnologia Agraria e Forestale. these pulping processes to be optimized. In the present study, carbohydrate and lignin-containing fractions from a laboratory extraction of wheat straw with sodium hydroxide and lignin recovered from an industrial effluent from straw soda pulping were characterized by the above analytical techniques to contrast the information provided on the chemical nature and association between cell-wall polymers.

\section{EXPERIMENTAL PROCEDURES}

Materials Studied. Wheat (Triticum aestivum) straw (WS), collected in Zaragoza, Spain, was extracted with $80 \%$ ethanol in a Soxhlet $(16 \mathrm{~h})$. Details on the subsequent fractionation were given by Terrón et al. (1992). Alkali-soluble material was obtained by treating the alcohol-extracted straw with $1 \mathrm{M} \mathrm{NaOH}\left(30^{\circ} \mathrm{C}\right.$, $12 \mathrm{~h}$ ). The so-called hemicellulose fraction (HC) was recovered from the above solution by methanol precipitation, and the alkali lignin 1 fraction (AL1) was then precipitated (pH 2) from the supernatant solution (Janshekar et al., 1982). An additional lignin-containing fraction, labeled alkali lignin 2 (AL2), was obtained using a lower $\mathrm{NaOH}$ concentration $(0.25 \mathrm{M})$. The industrial effluent was collected after biological (anaerobic and aerobic) treatment of wastewater containing black and white liquors from semichemical soda pulping of the same straw in an atmospheric pulper. After elimination of suspended solids and methanol precipitation, the effluent alkali lignin (ALE) was precipitated at $\mathrm{pH}$ 2. Klason lignin content in different fractions and whole straw was estimated as the ash-free residue after Saeman's hydrolysis of straw polysaccharides (Effland, 1977). Neutral sugars in the hydrolysates were analyzed as alditol acetates by gas chromatography (TAPPI, 1975).

Spectroscopic Analyses. For IR spectroscopy $2 \mathrm{mg}$ of sample in $300 \mathrm{mg}$ of $\mathrm{KBr}$ was used. Solid-state ${ }^{13} \mathrm{C} \mathrm{NMR}$ spectra were obtained in a Bruker MSL 300 spectrometer at $75.4 \mathrm{MHz}$ with the CPMAS technique, under quantitative conditions (Frund and Lüdemann, 1989b). The pulse repetition rate was $5 \mathrm{~s}$, the cross polarization (CP) contact time was $1 \mathrm{~ms}$, the sweep width was $31.25 \mathrm{kHz}$, the filter width was set to $37.5 \mathrm{kHz}$, and the acquisition time was $0.016 \mathrm{~s}$. Magic-angle spinning (MAS) was performed at $4 \mathrm{kHz}$ in double-bearing probes in phase-stabilized $\mathrm{ZrO}_{2}$ rotors. The chemical shift was calibrated with glycine. Estimation of the $S$ and $G$ components in the 165-125 ppm 
Table I. Klason Lignin and Major Polysaccharide Sugars in the Wheat Straw Fractions

\begin{tabular}{lclll}
\hline & \multirow{2}{*}{\begin{tabular}{c} 
Klason \\
\cline { 3 - 5 }
\end{tabular}} & \multicolumn{3}{c}{ polysaccharide $^{a}$} \\
\cline { 3 - 5 } & lignin $^{a}$ & glucose & xylose & arabinose \\
\hline wheat straw (WS) & 16.6 & 37.1 & 16.4 & 3.3 \\
hemicellulose (HC) & 4.6 & 4.9 & 56.7 & 6.3 \\
alkali lignin 1 (AL1) & 80.9 & 1.2 & 12.7 & 3.4 \\
alkali lignin 2 (AL2) & 56.1 & 3.8 & 24.7 & 4.4 \\
effluent alkali lignin (ALE) & 78.7 & tr $^{b}$ & tr & tr
\end{tabular}

a $/ 100 \mathrm{~g}$ of sample. ${ }^{b} \mathrm{tr}=$ traces.

aromatic region of the NMR spectra was carried out by digital subtraction of a softwood (G-lignin) spectrum (Manders, 1987; Martinez et al., 1991). After a zero subtraction value was obtained in the 146-148 ppm region, $S$ and $G$ components were obtained. The S/G ratio was calculated after area integration of both components and normalization to the same number of substituted aromatic carbons.

Analytical Pyrolysis (Py-GC-MS). Samples (approximately $1 \mathrm{mg}$ ) were pyrolyzed in a quartz sample holder at 600 ${ }^{\circ} \mathrm{C}$ for $5 \mathrm{~s}$, using a platinum filament pyrolyzer (CDS pyroprobe 100 ) coupled to a gas chromatograph which was interfaced to an ion trap detector (ITD) mass spectrometer. The gas chromatograph was fitted with a SPB-5 column programmed from 50 to $250^{\circ} \mathrm{C}$ at $5^{\circ} \mathrm{C} / \mathrm{min}$, holding the initial temperature for $10 \mathrm{~min}$. Mass spectra were recorded under electron impact at $70 \mathrm{eV}$ from 40 to $350 \mathrm{~m} / z$ at $1 \mathrm{scan} / \mathrm{s}$. The pyrolyzer-GC interface was at $180^{\circ} \mathrm{C}$ and the GC-MS transfer line at $230^{\circ} \mathrm{C}$. Injection mode was split (approximately 1/100). Carrier gas was helium ( $1 \mathrm{~mL} /$ min). Product identification was performed on the basis of standards, the NBS library of spectra, and published spectra and gas chromatograms of lignocellulosic materials (Ralph and Hatfield, 1991). Relative molar abundances of the pyrolysis products were calculated by dividing peak areas by molecular weights.

CuO Degradation. One hundred milligrams of sample was degraded at $170^{\circ} \mathrm{C}\left(3 \mathrm{~h}, \mathrm{~N}_{2}\right)$ in Teflon bombs with $2 \mathrm{~g}$ of $\mathrm{CuO}$ $200 \mathrm{mg}$ of $\mathrm{Fe}\left(\mathrm{NH}_{4}\right)_{2}\left(\mathrm{SO}_{4}\right)_{2} \cdot 6 \mathrm{H}_{2} \mathrm{O}$, and $14 \mathrm{~mL}$ of $2 \mathrm{M} \mathrm{NaOH}$ (Hedges and Ertel, 1982). The degradation products were recovered with ethyl ether, suspended in $100 \mu \mathrm{L}$ of pyridine (ethylvanillin as internal standard), derivatized with BSTFA, and analyzed by GC-MS $\left(30 \mathrm{~m} \times 0.25 \mathrm{~mm} \mathrm{SP}-2100\right.$ column, $100-270^{\circ} \mathrm{C}$ at 4 ${ }^{\circ} \mathrm{C} / \mathrm{min}$, helium as carrier gas) using an ITD, under conditions described above. Quantitations were based on the area of the internal standard and the response factors obtained from standard compounds, and molar abundances of lignin degradation products were calculated.

\section{RESULTS AND DISCUSSION}

The major constituents of the wheat straw fractions studied are presented in Table I. Additional information on these samples was reported elsewhere (Terrón et al., 1992). As expected, the greatest Klason lignin content was found in the alkali lignin 1 (AL1) and effluent alkali lignin (ALE) fractions, but some amount of lignin was present in the hemicellulose (HC) fraction. Different amounts of carbohydrate were present in the lignincontaining fractions AL1 and AL2. On the other hand, the ALE fraction was carbohydrate-free due to biological treatment of the industrial effluent. The straw hemicellulose appeared as an arabinoxylan (xylose/arabinose ratio of $9: 1$ ), and the high pentose/glucose ratio in the ALI and AL2 fractions, compared to that in whole straw, suggested association of lignin with the arabinoxylan. Moreover, the xylose/arabinose ratio $(10: 3)$ in the alkali lignin fraction AL1 revealed that the percentage of arabinose units linked to lignin (as percent of total arabinose) was higher than the percentage of linked xylose, in accordance with the findings of Xiao-an et al. (1989).

Spectroscopic Analyses. The IR spectra of the four straw fractions are shown in Figure 1. The most prominent bands in these spectra correspond to (i) lignin $(1600,1510$,
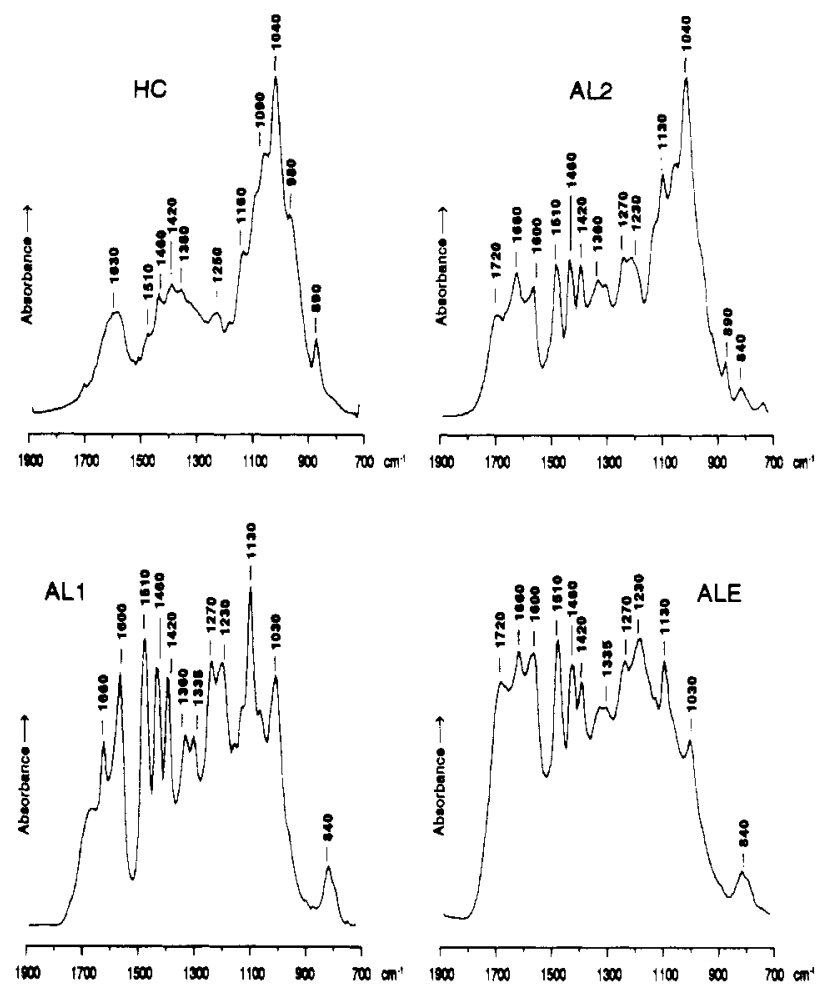

Figure 1. IR spectra of the wheat straw fractions $(\mathrm{HC}=$ hemicellulose, $\mathrm{AL} 1$ = alkali lignin 1, AL2 = alkali lignin 2, ALE $=$ effluent alkali lignin).

$1460,1420,1335,1270,1230,1130,1030$, and $840 \mathrm{~cm}^{-1}$ ) and (ii) carbohydrates $\left(1380,890 \mathrm{~cm}^{-1}\right.$ and the broad band around $1040 \mathrm{~cm}^{-1}$. Bands from carbonyl groups (e.g., in cinnamic acids or lipids) were also present at 1720 and $1660 \mathrm{~cm}^{-1}$

The NMR spectra of the four fractions are shown in Figure 2. Most of the signals corresponded to carbons in the different lignin units: $161 \mathrm{ppm}$ for $\mathrm{C}_{4}$ in $\mathrm{H} ; 153 \mathrm{ppm}$ for $\mathrm{C}_{3}$ and $\mathrm{C}_{5}$ in $\mathrm{S}$ (etherified); $148 \mathrm{ppm}$ for $\mathrm{C}_{3}$ and $\mathrm{C}_{4}$ in $\mathrm{G}$ (etherified) and for $\mathrm{C}_{3}$ and $\mathrm{C}_{5}$ in $\mathrm{S}$ (phenolic); $146 \mathrm{ppm}$ for $\mathrm{C}_{4}$ in $\mathrm{G}$ (phenolic); $134 \mathrm{ppm}$ for $\mathrm{C}_{1}$ and $\mathrm{C}_{4}$ in $\mathrm{S}$ and for $\mathrm{C}_{1}$ in $\mathrm{G} ; 128 \mathrm{ppm}$ for $\mathrm{C}_{2}$ and $\mathrm{C}_{6}$ in $\mathrm{H} ; 114 \mathrm{ppm}$ for $\mathrm{C}_{6}$ in G; $105 \mathrm{ppm}$ for $\mathrm{C}_{2}$ and $\mathrm{C}_{6}$ in $\mathrm{S} ; 84 \mathrm{ppm}$ for $\mathrm{C}_{\beta}$ in $\beta-0-4$; $74 \mathrm{ppm}$ for $\mathrm{C}_{\alpha}-\mathrm{OH}$ in $\beta-0-4$; and $56 \mathrm{ppm}$ for methoxy $\mathrm{C}$. Signals from phenolic units are more evident in lignin from wheat straw than from hardwoods, as a consequence of its relatively high ( $\mathrm{ca} .20 \%$ ) phenolic content (Kühn et al., 1992). Several signals corresponded to polysaccharide unit carbons: $103 \mathrm{ppm}$ for $\mathrm{C}_{1} ; 75 \mathrm{ppm}$ for $\mathrm{C}_{2}, \mathrm{C}_{3}$, and $\mathrm{C}_{5}$; 65 ppm for $C_{6}$. Finally, two other signals were present: $172 \mathrm{ppm}$ for carbonyl $\mathrm{C}$ and $31 \mathrm{ppm}$ for nonsubstituted alkyl $\mathrm{C}$ (e.g., in lipids).

The IR and NMR spectra of the HC and AL1 fractions were characteristic of polysaccharide and lignin, respectively (Martínez et al., 1991b; Almendros et al., 1992), including the diagnostic peaks listed above. The AL1 spectra were nearly identical to the spectrum of milledstraw lignin extracted according to the Björkman (1956) method (not shown). In the HC fraction, the broad band at $1630 \mathrm{~cm}^{-1}$ was probably due to linked water, and the small bands at 1460,1420 , and $1510 \mathrm{~cm}^{-1}$ showed low lignin content (Table I) in this fraction. The absence of carbonyl and methyl $\mathrm{C}$ signals in the NMR spectrum suggested a low amount of acetyl groups in the HC fraction.

On the other hand, the spectra of the AL2 fraction evidenced a mixed pattern, which can be described in terms of the overlapping of polysaccharide and lignin bands. The NMR spectrum included all of the above carbohydrate 


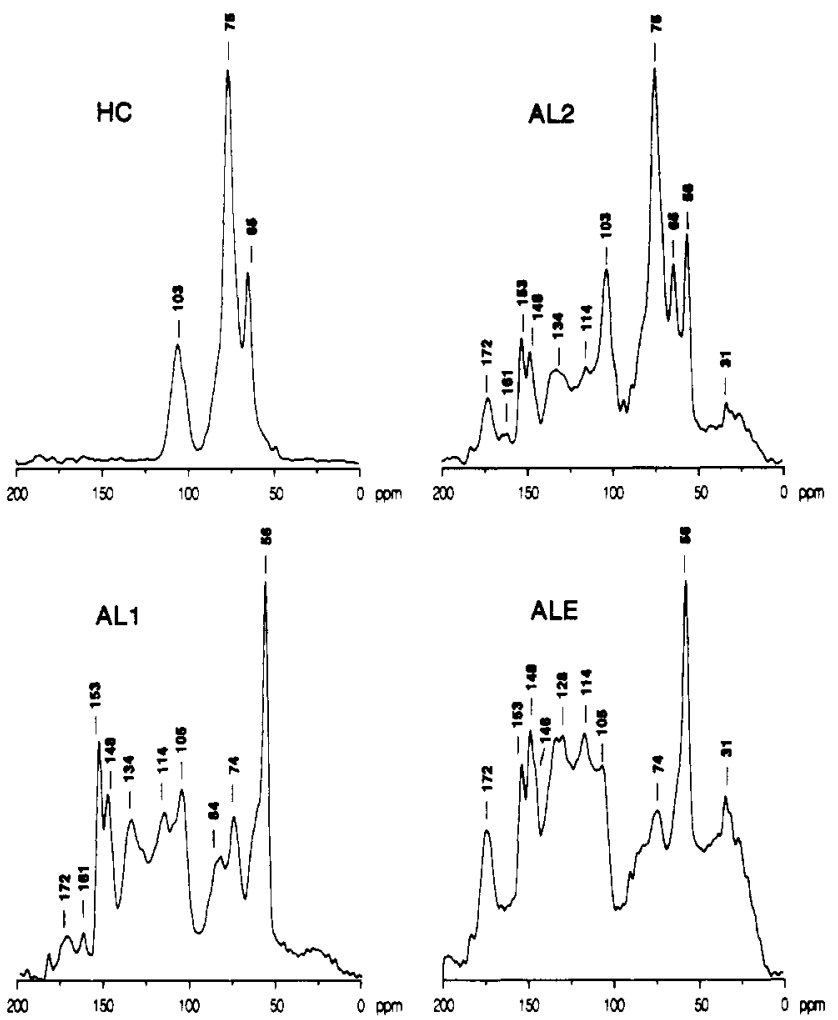

Figure 2. CPMAS ${ }^{13} \mathrm{C}$ NMR spectra of the wheat straw fractions (HC = hemicellulose, AL1 = alkali lignin 1, AL2 = alkali lignin 2, ALE = effluent alkali lignin).

and lignin signals, whereas the IR spectrum showed most lignin bands in addition to those of carbohydrates at 1040 and $890 \mathrm{~cm}^{-1}$.

Finally, the spectra of the ALE fraction were similar to those of the AL1 fraction, but they evidence modifications of the lignin polymer due to the anaerobic and aerobic treatments of the industrial effluent. The most significant features showed by the IR spectrum were the strong bands of unconjugated and conjugated carbonyls at 1720 and $1660 \mathrm{~cm}^{-1}$, respectively (Hergert, 1971). The former band could correspond to microbial lipids, whereas that at 1660 $\mathrm{cm}^{-1}$ probably reflects oxidative alteration (formation of $\alpha$-carbonyl groups with or without side-chain breakdown) during biological treatment (Kirk and Farrell, 1987). The increased amount of carbonyl groups was also evidenced by the NMR spectrum, exhibiting an intense $172 \mathrm{ppm}$ signal, and the broad signal around $31 \mathrm{ppm}$ suggested microbial lipids. Some differences in aromatic $\mathrm{C}$ signals were observed when ALE was compared with the AL1 fraction. The increase of the $128 \mathrm{ppm}$ signal could be due to a high proportion of $\mathrm{H}$ units (see Table II and Figure 5), whereas an increased phenolic content could contribute to the $148 \mathrm{ppm}$ signal, including the $146 \mathrm{ppm}$ shoulder.

Py-GC-MS. The products obtained after pyrolysis of the straw fractions (Figure 3 ) were ascribed to the thermal decomposition of the main plant polymers, according to Martin et al. (1979), Mulder et al. (1991), and Ralph and Hatfield (1991). A series of pyrolysis products from phenylpropanoid structures (i.e., lignin and cinnamic acids), including phenol, guaiacol, and syringol and their para methyl, ethyl, vinyl, and propenyl derivatives, were also identified. The origin of most of them can be straightforwardly deduced as derived from $H$ (peaks 5,9 , and 14 in Figure 3), G (peaks 10, 13, 16, 17, 19, 20, 22, 23, 25 , and 27), and $S$ (peaks 18, 21, 24, 26, and 28-34) lignin units or cinnamic acids, and Py-GC-MS molar H/G/S ratios were calculated (Figure 5). 3,4-Dihydroxybenzal- dehyde (peak 12) was only found in the HC fraction, whereas 3-methoxycathechol (peak 15) appeared in the three lignin-containing fractions ( $\mathrm{AL} 1, \mathrm{AL} 2$, and $\mathrm{ALE}$ ) and could be derived from lignin demethylation during alkaline treatment. The lignin pyrolysis peaks were characteristic of the latter fractions, but some of them (peaks 10,17, 18, and 26) were identified also in the HC fraction. In addition, different products from polysaccharide pyrolysis (peaks 1-4, 6-8, and 11) were found mainly in pyrograms of the HC and AL2 fractions. In fact, after pyrolysis and spectroscopic analyses, the latter fraction can be considered as a lignin-polysaccharide complex.

When the relative abundances of the peaks corresponding to lignin pyrolysis products were compared with the Klason lignin content or with the low intensities of the NMR and IR lignin bands (160-110 ppm aromatic C region; and 1510,1460 , and $1420 \mathrm{~cm}^{-1}$ ), it appeared that pyrolysis led to some overestimation of lignin in the HC fraction. This was probably due to the higher yield of lignin-derived compounds under pyrolysis, when compared to the complex isomeric mixtures of dehydradation products from carbohydrates.

CuO Degradation. Cinnamic acids (peaks XI and XII) and products derived from $\mathrm{H}$ (peaks I, II, and VI), G (peaks III, V, and IX), and S lignin units (peaks VII, VIII, and $\mathrm{X}$ ) were identified after $\mathrm{CuO}$ alkaline degradation (Figure 4). Three types of aromatic compounds with different degrees of oxidation (i.e., aldehydes, ketones, and acids) were released after $\mathrm{CuO}$ degradation of each lignin unit. The small lignin amount in the HC fraction already suggested by the Py-GC-MS and the IR spectrum was confirmed after CuO degradation. The cinnamic acids were nearly absent in the HC fraction, but their trans isomers were among the most abundant compounds in the three lignin-containing fractions. Minor peaks for $c i s$ isomers are indicated on the chromatograms.

The above results suggested that cinnamic acids were linked to hemicellulose only by ester bonds, which were saponified by cold sodium hydroxide. On the other hand, their constant presence in the three lignin-containing fractions indicated significant amounts of nonsaponifiable linkages (such as ethers) between cinnamic acids and lignin. The low amount of $p$-coumaric acid in these fractions, compared with that in the whole straw, suggested that a considerable proportion of this compound was esterified with lignin. These results agree with models involving bridges between wheat straw hemicellulose and lignin through ferulic acid (Scalbert et al., 1985; Iiyama et al., 1990; Lam et al., 1992; Ralph et al., 1992).

Lignin Composition As Revealed by the Different Analytical Techniques. The molar H/G/S ratios in lignin and the amounts of cinnamic acids relative to lignin units were calculated from the results of $\mathrm{CuO}$ degradation (Table II). The high $\mathbf{S}$ content in the three lignincontaining fractions evidenced that the less condensed $\mathrm{S}$-lignin is readily extracted by sodium hydroxide. Preferential removal of S-lignin during alkali extraction from wheat straw was also reported by Lapierre et al. (1989). By contrast, the lignin included in the HC fraction presented the lowest $S / G$ ratio, especially when analyzed by pyrolysis, as expected after preferential removal by alkali of S-lignin. It is known that vinylphenol and vinylguaiacol are formed by pyrolytical decarboxylation of $p$-coumaric and ferulic acids, respectively (Boon, 1989; Galletti et al., 1991). However, they have also been found after pyrolysis of cinnamic-free lignin preparations (SaizJiménez and de Leeuw, 1984), as a result of the breakdown of $\mathbf{H}$ and $\mathrm{G}$ lignin units. To compare with pyrolysis, the 

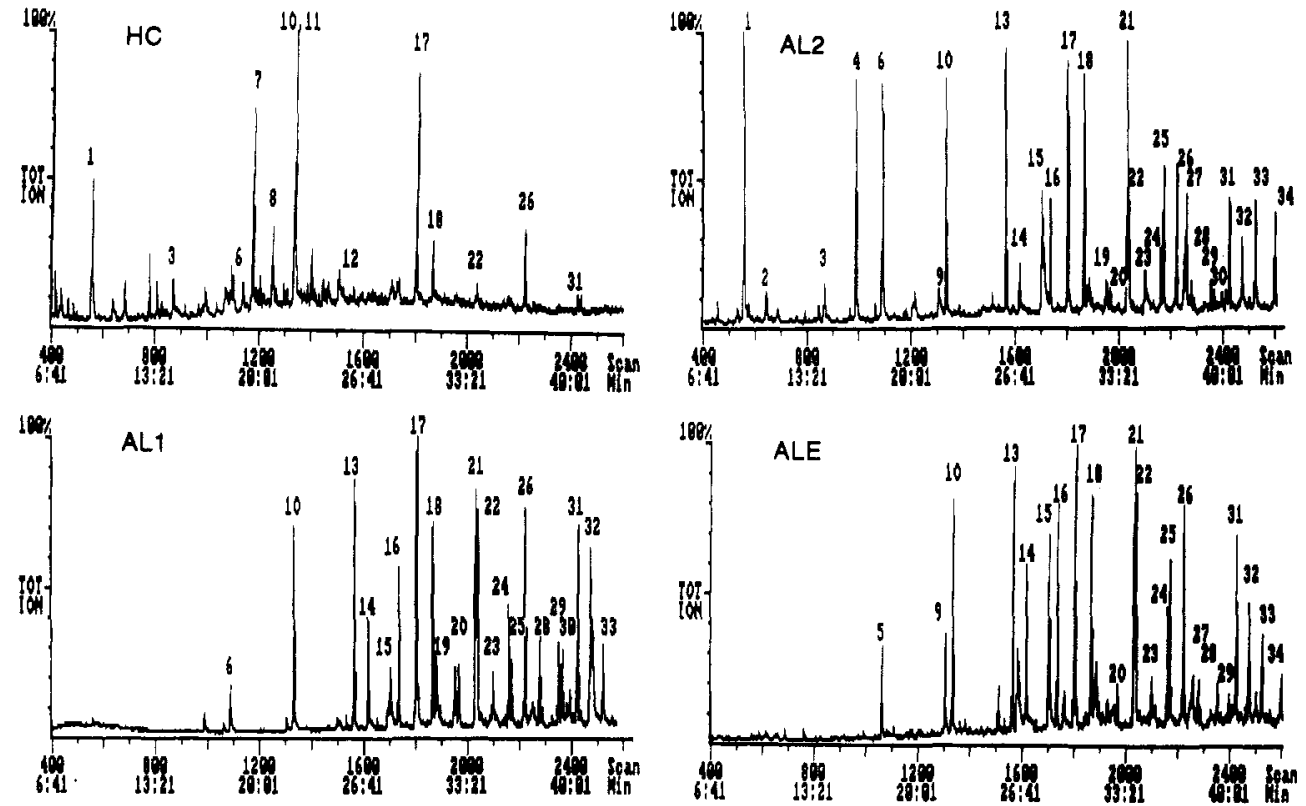

Figure 3. Py-GC-MS of the wheat straw fractions ( $\mathrm{HC}=$ hemicellulose, $\mathrm{AL1}=$ alkali lignin $1, \mathrm{AL2}=$ alkali lignin 2 , ALE $=$ effluent alkali lignin). 1 = 2-Furaldehyde; $2=2$-OH-Me-furan; $3=2,3$-dihydro-5-Me-furan-2-one; $4=N$-Et-furanone; $5=$ phenol; $6=4$ - $0 H$ 5,6-dihydro-(2H)-pyran-2-one; $7=2$-OH-3-Me-2-cyclopenten-1-one; $8=$ diMe-dihydropyranone; $9=p$-cresol; $10=$ guaiacol; $11=$ levoglucosenone; 12 = 3,4-diOH-benzaldehyde; 13 = 4-Me-guaiacol; 14 = 4-vinylphenol; 15 = 3-MeO-catechol; $16=4$-Et-guaiacol; 17 $=4$-vinylguaiacol; $18=$ syringol; $19=$ vanillin; $20=$ cis-isoeugenol; $21=4-\mathrm{Me-syringol;} 22=$ trans-isoeugenol; $23=$ acetovanillone; 24 = 4-Et-syringol; 25 = guaiacylacetone; 26 = 4-vinylsyringol; 27 = guaiacyl vinyl ketone; 28 = 4-allylsyringol; $29=$ cis-4-propenylsyringol; $30=$ syringaldehyde; $31=$ trans-4-propenylsyringol; $32=$ acetosyringone; $33=$ syringylacetone; $34=$ propiosyringone.
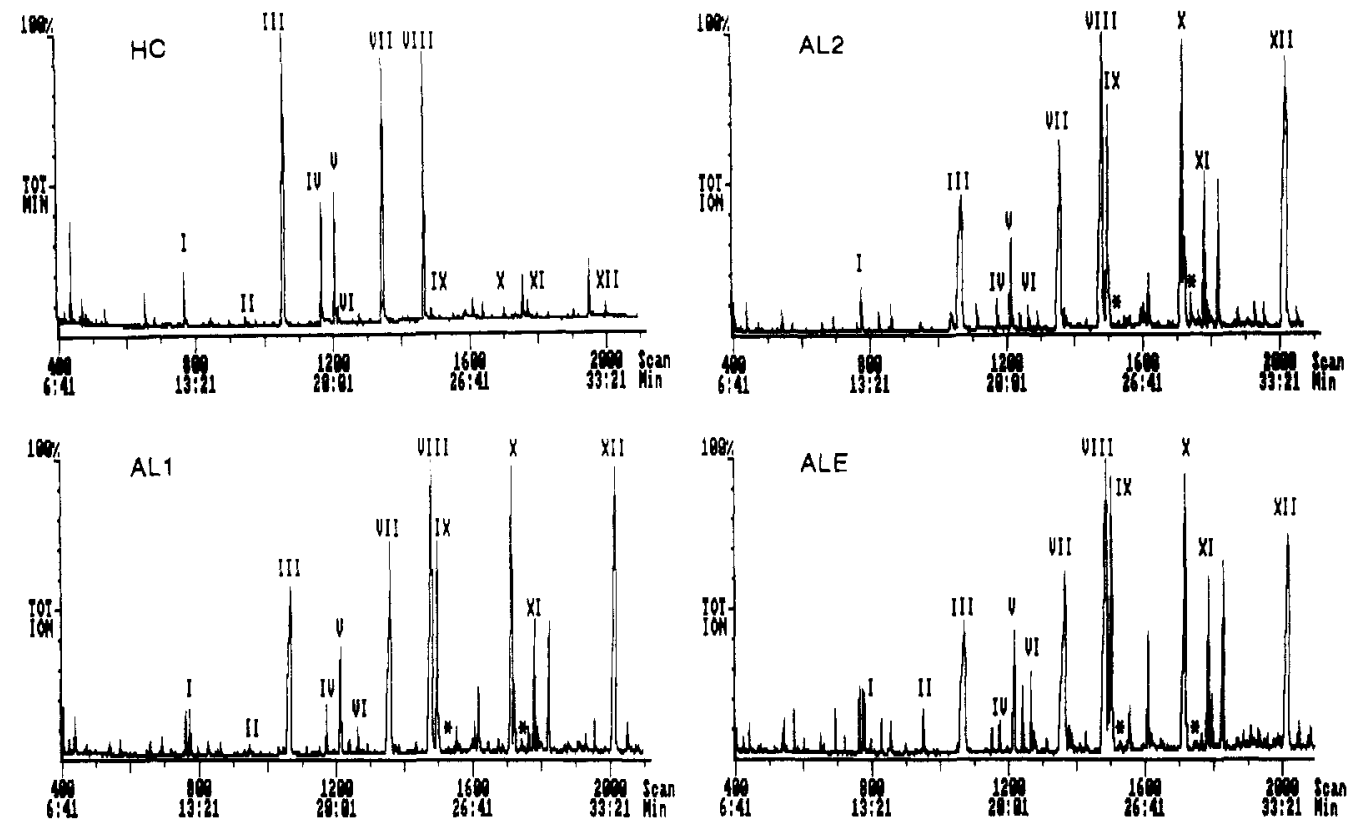

Figure 4. GC-MS analysis of lignin and cinnamic acids after $\mathrm{CuO}$ degradation of the straw fractions (HC $=$ hemicellulose, AL1 $=$ alkali lignin 1, AL2 = alkali lignin 2, ALE = effluent alkali lignin). I = p-OH-benzaldehyde; II = $p$-OH-acetophenone; III = vanillin; IV = ethylvanillin (standard); $\mathrm{V}=$ acetovanillone; VI = $p-\mathrm{OH}$-benzoic acid; VII = syringaldehyde; VIII = acetosyringone; IX = vanillic acid; $\mathrm{X}=$ syringic acid; $\mathrm{XI}=$ trans-p-coumaric acid; $\mathrm{XII}=$ trans-ferulic acid; $*$ = cis isomers of $\mathrm{XI}$ and $\mathrm{XII}$.

$\mathrm{H} / \mathrm{G} / \mathrm{S}$ ratios after $\mathrm{CuO}$ degradation were recalculated including cinnamic acids. Some differences between the lignin compositions deduced from both techniques were observed (Figure 5).

In general, it is assumed that $\mathrm{CuO}$ degradation breaks predominantly ether linkages in lignin, whereas different $\mathrm{C}-\mathrm{C}$ bonds can be cleaved by pyrolysis (Galletti et al., 1991). The highest $\mathrm{G}$ yield after pyrolysis of the straw fractions pointed to a more extensive lignin depolymerization, affecting also $\mathrm{C}_{5}-\mathrm{C}_{5^{\prime}}$ bonds in condensed G-lignin. Among the different fractions, the lowest $S / G$ ratio was found in HC. Since cinnamic acids were nearly absent from this fraction (Table II), the G-type compounds identified after pyrolysis were considered to derive from lignin, suggesting specific association between hemicellulose and G-lignin through nonsaponifiable bonds. The earlier deposition of G-lignin during monocotyledons lignification (He and Terashima, 1991) could facilitate linkages between G-units and hemicellulose in the cell wall. These results also suggest that some $\mathrm{C}-\mathrm{C}$ linkages, cleaved by pyrolysis but resistant to $\mathrm{CuO}$ degradation, were present in lignin associated to hemicellulose.

The intensities of 1335- and $1270-\mathrm{cm}^{-1}$ IR bands, assigned to $\mathrm{S}$ - and G-ring breathing respectively (Hergert, 
Table II. H/G/S Molar Ratio in Lignin and Cinnamic Acid Content in the Wheat Straw Fractions As Revealed by CuO Degradation

\begin{tabular}{lccc}
\hline & & \multicolumn{2}{c}{ cinnamic acidsa } \\
\cline { 3 - 4 } & H/G/S ratio & p-coumaric & ferulic \\
\hline wheat straw (WS) & $8: 41: 51$ & 28.9 & 37.4 \\
hemicellulose (HC) & $5: 45: 49$ & 0.9 & 0.8 \\
alkali lignin 1 (AL1) & $4: 34: 62$ & 5.8 & 25.0 \\
alkali lignin 2 (AL2) & $4: 31: 65$ & 5.9 & 24.3 \\
effluent alkali lignin (ALE) & $9: 33: 57$ & 5.5 & 12.1 \\
a mol/100 mol of etherified lignin (=H $+\mathrm{G}+\mathrm{S}$ ). ${ }^{b} \mathrm{H}=$ p-hy- \\
droxyphenyl; G = guaiacyl; S = syringyl.
\end{tabular}

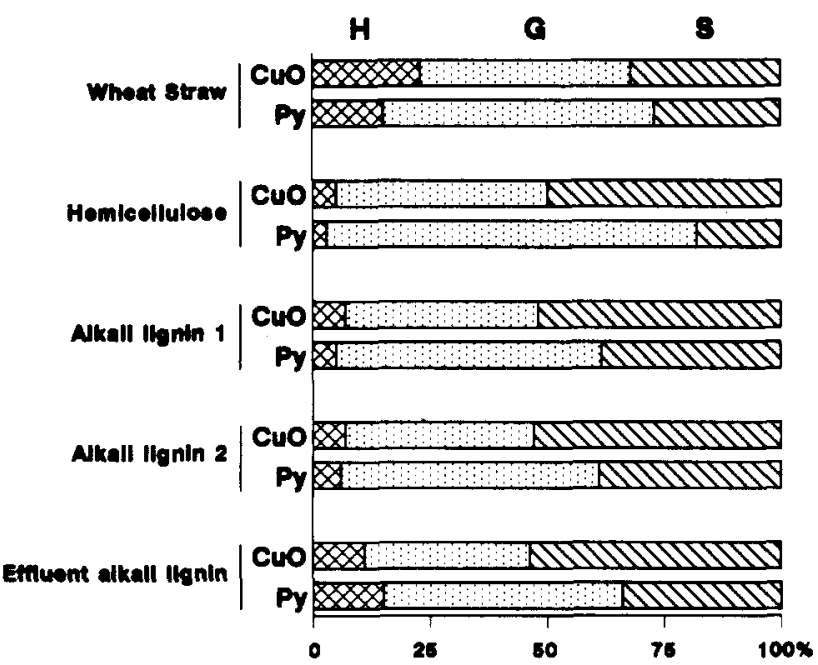

Figure 5. Quantitative comparison of $p$-hydroxyphenyl $(\mathrm{H})$, guaiacyl (G), and syringyl (S) molar ratios (cinnamic acids included) through alkaline degradation $(\mathrm{CuO})$ and pyrolysis (Py).

1971), suggested high $G$ content in wheat straw lignin, when compared with lignin from hardwoods. This was supported by the relative intensities of 153 and $148 \mathrm{ppm}$ NMR signals. However, accurate determination of $S / G$ ratios according to the method described by Manders (1987) (based on the assumption that the $148 \mathrm{ppm}$ signal in wood can be entirely attributed to G-lignin) was difficult due to the structural complexity of grass lignins. In fact, the $148 \mathrm{ppm}$ signal also included $\mathrm{C}_{3}$ and $\mathrm{C}_{5}$ in phenolic S-units and overlapped with the $146 \mathrm{ppm}$ signal of $\mathrm{C}_{4}$ in phenolic G-structures. In spite of this limitation, an $\mathrm{S} / \mathrm{G}$ ratio of 0.5 was estimated for laboratory alkali lignins (AL1 and AL2 fractions) by obtaining the $S$ and $G$ components of the aromatic region of the NMR spectra. The comparatively low $153 \mathrm{ppm}$ signal in the ALE fraction could suggest the lowest $S / G$ ratio among the alkali lignin fractions, but this assumption was not supported by the $\mathrm{S} / \mathrm{G}$ values from the degradative techniques. A more consistent explanation could be that the high $146-148 \mathrm{ppm}$ band in the ALE spectrum (Figure 2) was the sum of different signals, including those due to phenolic units in lignin.

In general, the four techniques used gave complementary information on chemical composition of plant polymers in the straw fractions. CPMAS ${ }^{13} \mathrm{C}$ NMR and IR provided generic, but significant and unequivocal, information on the nature of whole samples. More details were obtained after polymer degradation, but partial depolymerization was an important drawback of the degradative techniques. This fact was evidenced by differences in S/G ratios obtained by three techniques (CuO oxidation $>$ pyrolysis $>$ NMR), due to the more recalcitrant nature of G-lignin toward depolymerization. Cupric oxide degradation seemed to be a suitable technique for analyzing straw lignin since it (as opposed to other chemical degradation procedures, e.g., nitrobenzene oxidation) led to separate estimation of lignin units and cinnamic acids. This distinction, which represents an important point when grass materials are analyzed, cannot be achieved by pyrolysis, but the latter technique provided a more extensive degradation of the lignin polymer and gave information on other plant constituents.

\section{ACKNOWLEDGMENT}

We acknowledge Prof. H.-D. Lüdemann for the use of the solid-state NMR facilities at Regensburg University, Dr. A. Prieto for her help with GC-MS analyses, and Dr. G. Almendros for critical reading of the work. The Action COST84ter of the European Community funded the stay of M.C. Terrón in Bologna (Centro Conservazione Foraggi, CNR) where the Py-GC-MS work was done. This research has been supported by the ECLAIR Project "Upgrading straw into pulp, paper and polymeric materials" (EC Contract AGRE-0044).

\section{LITERATURE CITED}

Almendros, G.; Martinez, A. T.; González, A. E.; González-Vila, F. J.; Fründ, R.; Lüdemann, H.-D. CPMAS 13C NMR study of lignin preparations from wheat straw transformed by five lignocellulose-degrading fungi. J. Agric. Food Chem. 1992, 40, 1297-1302.

Björkman, A. Studies on finely divided wood. Part I. Extraction of lignin with neutral solvents. Sven. Papperstidn. 1956, 13, 477-485.

Boon, J. J. An introduction to pyrolysis mass spectrometry of lignocellulosic materials: Case studies on barley straw, corn stem and Agropyron. In Physico-Chemical Characterization of Plant Residues for Industrial and Feed Use; Chesson, A., Orskov, E. R., Eds.; Elsevier Applied Science: London, 1989; pp 25-49.

Effland, M. J. Modified procedure to determine acid-insoluble lignin in wood and pulp. Tappi 1977, 60, 143-144.

Fründ, R.; Lüdemann, H.-D. ${ }^{13}$ C-NMR Spectroscopy of Lignins and Lignocellulosic Materials. In Physico-Chemical Characterization of Plant Residues for Industrial and Feed Use; Chesson, A., Orskov, E. R., Eds.; Elsevier Applied Science: Amsterdam, 1989a; pp 110-117.

Fründ, R.; Lüdemann, H.-D. The quantitative analysis of solution and CPMAS-C-13 NMR spectra of humic material. Sci. Total Environ. 1989b, 81/82, 157-168.

Galletti, G. C.; Ward, R. S.; Pelter, A. Analysis of pyrolysis products of lignans using capillary gas chromatography and ion trap detection. J. Anal. Appl. Pyrolysis 1991, 21, 281-292.

He, L.; Terashima, N. Formation and structure of lignin in Monocotyledons. IV. Deposition process and structural diversity of the lignin in the cell-wall of sugarcane and rice plant studied by ultraviolet microscopic spectroscopy. Holzforschung 1991, 45, 191-198.

Hedges, J. I.; Ertel, J. R. Characterization of lignin by gas capillary chromatography of cupric oxide oxidation products. Anal. Chem. 1982, 54, 174-178.

Hergert, H. L. Infrared Spectra. In Lignins. Occurrence, Formation, Structure and Reactions; Sarkanen, K. V., Ludwig, C. H., Eds.; Wiley: New York, 1971; pp 267-297.

Higuchi, T. Lignin biochemistry: Biosynthesis and biodegradation. Wood Sci. Technol. 1990, 24, 23-63.

Iiyama, K.; Lam, T. B. T.; Stone, B. A. Phenolic acid bridges between polysaccharides and lignin in wheat internodes. Phytochemistry 1990, 29, 733-737.

Janshekar, H.; Haltmeier, T.; Brown, C. Fungal degradation of pine and straw alkali lignins. Eur. J. Appl. Microbiol. Biotechnol. 1982, 14, 174-181.

Kirk, T. K.; Farrell, R. L. Enzymatic "combustion": The microbial degradation of lignin. Annu. Rev. Microbiol. 1987, 41, 465505. 
Kühn, S.; Camarero, S.; Valmaseda, M.; Almendros, G.; Martínez, M. J.; González, A. E.; Martínez, A. T. Straw biopulping: Selective delignification with Pleurotus eryngii. In Biotechnology in Pulp and Paper Industry; Kuwahara, M., Shimada, M., Eds.; UNI: Tokyo, 1992; pp 15-20.

Lam, T. B. T.; liyama, K.; Stone, B. A. Cinnamic acid bridges between cell wall polymers in wheat and Phalaris internodes. Phytochemistry 1992, 31, 1179-1183.

Lapierre, C.; Jouin, D.; Monties, B. Lignin characterization of wheat straw samples as determined by chemical degradation procedures. In Physico-Chemical Characterization of Plant Residues for Industrial and Feed Use; Chesson, A., Orskov, E. R., Eds.; Elsevier Applied Science: Amsterdam, 1989; pp $118-130$.

Manders, W. F. Solid-state 13C NMR determination of the syringyl/guaiacyl ratio in hardwoods. Holzforschung 1987, 41, 13-18.

Marley, M. E. Straw pulp-A valuable raw material. Paper Pulp Int. 1991, 69-70.

Martín, F.; Saiz-Jiménez C.; González-Vila, F. J. Pyrolysis-gas chromatography-mass spectrometry of lignins. Holzforschung $1979,33,210-212$.

Martínez, A. T.; González, A. E.; Prieto, A.; González-Vila, F. J.; Fründ, R. $p$-Hydroxyphenyl:guaiacyl:syringyl ratio of lignin in some Austral hardwoods estimated by CuO-oxidation and solid-state NMR. Holzforschung 1991a, 45, 279-284.

Martínez, A. T.; González, A. E.; Valmaseda, M.; Dale, B. E.; Lambregts, M. J.; Haw, J. F. Solid-state NMR studies of lignin and plant polysaccharide degradation by fungi. Holzforschung 1991b, 45 (Suppl.), 49-54.

Mulder, M.; Pureveen, J. B. M.; Boon, J. J.; Martinez, A. T. An analytical pyrolysis mass spectrometry study of Euchryphia cordifolia wood decayed by white-rot and brown-rot fungi. $J$. Anal. Appl. Pyrolysis 1991, 19, 175-191.

Ralph, J.; Hatfield, R. D. Pyrolysis-GC-MS characterization of forage materials. J. Agric. Food Chem. 1991, 39, 1426-1437.

Ralph, J.; Helm, R. F.; Quideau, S.; Hatfield, R. D. Lignin-feruloyl ester cross-links in grasses. Part 1. Incorporation of feruloyl esters into coniferyl alcohol dehydrogenation polymers. $J$. Chem. Soc., Perkin Trans. 1 1992, 2961-2969.

Saiz-Jiménez, C.; de Leeuw, J. W. Pyrolysis-gas chromatographymass spectrometry of isolated, synthetic and degraded lignins. Org. Geochem. 1984, 6, 417-422.

Scalbert, A.; Monties, B.; Lallemand, J.-Y.; Guittet, E.; Rolando, C. Ether linkage between phenolic acids and lignin fractions from wheat straw. Phytochemistry 1985, 24, 1359-1362.

TAPPI. "Carbohydrate composition of extractive-free wood and wood pulp by gas-liquid chromatography", Tappi Rule T 249pm, 1975.

Terrón, M. C.; Calvo, A. M.; Fidalgo, M. L.; Manzanares, P.; Ballesteros, M.; Martínez, A. T.; Martín, C.; González, A. E. Chemical characterization and fungal decolorization of straw soda pulping effluents. In Biotechnology in Pulp and Paper Industry; Kuwahara, M., Shimada, M., Eds.; UNI: Tokyo, 1992; pp 51-56.

Xiao-an, L.; Zhong-zheng, L.; Die-sheng, T. Fractional studies on the characteristics of high alkali-soluble lignins of wheat straw. Cellul. Chem. Technol. 1989, 23, 559-572.

Received for review March 23, 1993. Accepted June 23, 1993.

- Abstract published in Advance ACS Abstracts, September 1, 1993. 